\title{
Ligações narrativas: o uso do link no cinema e nas novas mídias digitais
}

Egle Müller SpinelLI Universidade de São Paulo /ECA-USP 


\section{Resumo}

Este artigo pretende realizar uma reflexão sobre algumas semelhanças entre a linguagem cinematográfica e as chamadas novas mídias digitais, no que diz respeito à existência de filmes que desenvolvem recursos narrativos e estéticos que funcionavam como conectores (links) de outros contextos, um processo que amplia o significado da obra e é inerente às novas mídias.

\section{Palavras-chave}

cinema, mídias digitais, link, narrativa não-linear, interatividade

\section{Abstract}

The aim of this article is to make some reflections on the similarities of the cinematographer language and the so called digital new media, by relating the developing narrative and aesthetics aspects of films working as links for different contexts, which is a process that amplifies the significance of the film and is intrinsic to the new media.

Key words

cinema, new media, link, no linear narrative, interactivity 


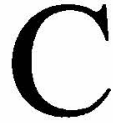

om o advento das novas mídias digitais ${ }^{1}$, iniciou-se uma busca pela instauração de características específicas deste novo meio áudio-vídeo-textual. A narrativa em hipermídia ${ }^{2}$, vista como um veículo de comunicação e entretenimento, é colocada como um modelo em discussão por se encontrar ainda em uma fase inicial de desenvolvimento. Assim, por conter a união de diferentes linguagens, como a literatura, a música e o cinema, muitas são as pesquisas que optam em realizar um estudo da influência destas artes na constituição de uma linguagem narrativa hipermidiática. $\mathrm{Na}$ tentativa de se chegarem a conceitos que sejam particulares deste novo meio, principalmente no que diz respeito à composição da imagem representada, optou-se em realizar um estudo paralelo com a linguagem do cinema.

1 Segundo Manovich, as novas mídias constituem expressões artísticas criadas por meio de recursos digitais ou convertidas de um suporte analogico para digital, formadas por códigos digitais e compostas por representações numéricas processadas em computadores, tais como vídeos, fotografias, textos, CD-roms, jogos, DVDs, realidades virtuais, cinemas digitais, os sites da Web, os ambientes e mundos virtuais, os games de computador e de consoles computadorizados, as instalaçōes interativas por computador, as animações com imagens reais e sintéticas por computador, multimídias e demais interfaces humano-computador (Manovich, 2001, p. 27).

2 Hipermídia é o meio em que o campo das novas midias se encontra. Segundo Bairon, hipermidia é a integração, sem suturas, de dados, textos, imagens de todas as espécies e sons dentro de um único ambiente de informação digital (Bairon \& Petry, 2000, p. 7). O hipertexto, termo muito utilizado para designar este processo, é um caso particular de hipermídia que usa um único tipo de mídia: o texto. Segundo Landow, o termo hipertexto foi denominado por Ted Nelson em 1960, para se referir a uma estrutura não seqüencial formada por um texto lido em uma tela interativa, que se ramifica e permite ao leitor realizar escolhas múltiplas. De acordo com a noção popular, trata-se de uma série de blocos conectados por links, oferecendo ao usuário diferentes itinerários (Landow, 1992, p. 4). Muitos tébricos como Landow, fazem as distinções acima, porém as utilizam com a mesma funcionalidade. 
Os ambientes hipermidiáticos tendem a trabalhar com diversos recursos de composição visual e sonora com o intuito de construir a representação de uma realidade que transporte o usuário/espectador para um mundo artificial e o faça acreditar que faz parte dele. Para isso, a hipermídia utiliza referências de outras manifestações artísticas anteriores, principalmente o cinema, que é uma das artes que mais evoluíram em termos de retratar a ilusão de uma realidade semelhante à qual se vive.

Na história do cinema sempre existiram tendências que buscaram desenvolver uma linguagem audiovisual em que o espectador, ao assistir ao filme, participasse de um mundo fictício como um observador que fosse cúmplice da história contada. Mesmo não podendo interferir no desenrolar dos eventos, ao espectador eram dados os melhores pontos de vista sobre determinado acontecimento, com o intuito de fazê-lo compreender perfeitamente a história sem que percebesse os artifícios utilizados para produzir esta realidade artificial. Assim, por meio dos recursos de composição de imagem e som, o espectador esquecia-se da sua própria realidade, adentrava em uma outra dimensão, identificava-se com os personagens e experimentava a história de seus pontos de vista. O cinema americano, desde o início ${ }^{3}$ apostou nesta forma de entretenimento, e desenvolveu alguns princípios relativos ao que se denomina de narrativa clássica, na qual a história é contada sem que se chame a atenção para os mecanismos narrativos audiovisuais que a constituem. Até os dias de hoje, este tipo de filme faz grandes sucessos de bilheteria, o que chama a atenção para uma preferência do público por filmes que o conduzam através da narrativa e não demandem algum tipo de reflexão crítica sobre ao que assistem.

Em contrapartida, sempre existiram vanguardas que caminharam num sentido oposto à estrutura linear e naturalista.estabelecida pela narrativa clássica. É interessante notar que, nos anos 20 , em vários lugares do mundo surgiram movimentos que negavam os

3 Em 1915, o filme The Birth of a Nation (O Nascimento de uma Nação - 1915), do diretor norte-americano David Wark Griffith, reuniu diversos elementos de composição audiovisual e consolidou alguns princípios formadores da linguagem cinematográfica. 
valores estéticos tradicionais incorporados pelo cinema clássico e quebravam completamente o universo ficcional pela incorporação de imagens articuladas de maneira não causal e, muitas vezes, sem nenhuma lógica. Como exemplos, podem-se citar a Vanguarda Francesa, representada por realizadores como Germaine Dulac e René Clair, bem como o movimento russo "The New Vision", representado por Moholy-Nagy, Rodchenko e .Vertov, que foram precursores de uma nova mobilidade de fotografia e de filmagem, e realizaram pontos de vista não convencionais como partes-chave de suas poéticas, utilizando sobreposições de imagens e ângulos de câmera inusitados. Também nesta época, não se pode deixar de citar os movimentos expressionistas e surrealistas que buscavam recursos narrativos e expressivos completamente opostos a uma representação fiel da realidade. Desta maneira, o cinema era utilizado como uma expressão que demandava uma participação do espectador na sua concepção, seja com relação ao assunto tratado ou ao próprio processo de produção de uma realidade falseada.

As novas mídias digitais parecem trabalhar com estes dois efeitos de sentido: provocam uma imersão do espectador, ao mesmo tempo em que exigem dele uma atitude na condução do desenrolar dos acontecimentos. Como o cinema, a hipermídia constitui-se da linguagem de vários meios (vídeo, som, gráficos, textos) e pode apresentar um percurso não-linear. As estruturas narrativas não-lineares podem ser discutidas sob diversos prismas, como histórias que não respeitam o tempo cronológico ou aquelas que apresentam diversos pontos de vista sobre um mesmo fato em comum. Esta última é a que mais tem correlação com o que se pretende explorar, pois mesmo sendo o cinema um suporte que apresente uma estrutura em que o espectador não pode alterar a ordenação dos fatos, existem muitos filmes que tiveram a intenção de oferecer diversos pontos de vista sobre o mesmo evento, oferecendo ao espectador mais de um caminho a percorrer.

$\mathrm{O}$ assunto sobre a não-linearidade ${ }^{4}$, bem como o que também muitos autores chamam de multilinearidade, é freqüentemente

4 Janet $H$. Murray explica a questão referente às formas múltiplas, evita usar o 
apontado pelos teóricos das novas mídias como uma das principais características desta nova linguagem. Porém, é importante frisar que muitos foram os filmes que tiveram a preocupação de trabalhar com esta questão e fornecer ao espectador distintas possibilidades de ligações entre os eventos apresentados. Neste caso, o sentido do filme emerge da compreensão destes caminhos entrecruzados, em que múltiplas versões podem ser geradas a partir de uma mesma representação fundamental, sendo que cada uma delas terá suas próprias peculiaridades de eventos e de personagens. Histórias multilineares podem auxiliar na percepção de causas ou acontecimentos complexos, assim como na imaginação de diferentes desfechos para uma mesma situação. A fragmentação da estrutura da história possibilita modelos de leituras que fornecem múltiplas alternativas contraditórias. Assim, dentro de um mesmo filme surgem múltiplas opções que apresentam possibilidades distintas de um núcleo inicial em comum. $\mathrm{Na}$ cinematografia mundial, muitos são os exemplos encontrados, como o filme japonês Rashomon (1950), de Akira Kurosawa, o filme alemão Corra Lola, Corra (1998), de Tom Tykwer, o recente filme americano Efeito Borboleta (2004), de Eric Bress e J. Mackye Gruber, e os brasileiros Boca de Ouro (1968), de Nelson Pereira dos Santos, e Amores Possíveis (2001), de Sandra Werneck. Todos estes filmes apresentam múltiplas versões que acontecem segundo diferentes ações que são tomadas pelos mesmos personagens em relação a um acontecimento em comum.

Outra questão que caracteriza as novas mídias é a interatividade, processo em que o usuário pode interagir com a obra e escolher um caminho dentre as opções que são fornecidas no desenrolar da narrativa. A defesa da interatividade encontra-se em diversos estudos sobre as novas mídias como um elemento que as diferencia dos outros meios narrativos. Este posicionamento colocaa como um mecanismo restrito apenas às novas mídias, como se em outras artes, como o cinema, a interatividade não fosse possível. É

termo não-linear e chama de multi-seqüenciais ou multiformes as narrativas que proporcionam ao espectador a habilidade de entrar em contato com uma série fixa de eventos de diferentes maneiras, todas elas bem definidas e significativas. (Murray, 1997, p. 37-9) 
claro que as novas mídias, como os processos narrativos desenvolvidos em videogames e artes interativas, permitem que o usuário tenha o poder de decisão dentro de um contexto restrito de opções. Este fato fornece mais liberdade de escolha com relação ao espectador no cinema, que não pode alterar o que já foi pré-estabelecido pelo filme. Isso é realmente inovador, pois as novas mídias estão evoluindo a partir desta possibilidade de interação em que o usuário escolhe um caminho segundo a sua própria vontade, mesmo que ainda seja restrito. Esta questão permite voltar à arte cinematográfica e visualizar a existência de filmes que demonstram uma profunda preocupação em deixar espaços vazios para serem preenchidos com contextos ligados ao repertório e às experiências do espectador. Este processo permite a construção de um percurso significativo particular, um mecanismo cognitivo muito parecido pelo demandado nas novas mídias digitais, ao requerer um usuário/espectador ativo e participativo, que atualize os significados do texto a partir de conexões entre conteúdos distintos.

\section{Os links no cinema e nas novas mídias digitais}

Nos estudos relacionados às novas mídias digitais, é comum encontrar-se o termo lexia ${ }^{5}$, um conceito teórico estabelecido por Barthes para a determinação de blocos ou contextos de informações ligadas por meio de links. Os links, ou hiperlinks, são responsáveis pela conexão entre dois elementos, por exemplo, entre duas palavras em duas páginas diferentes da internet ${ }^{6}$, entre uma sentença em uma página e uma imagem em outra, entre dois diferentes lugares dentro de uma mesma página, etc. Tecnicamente, link é um elemento

5 Este termo é utilizado por Barthes para designar as unidades de leitura correspondentes a curtos fragmentos contíguos do texto narrativo que permitem ao leitor viver o plural do texto, captar as múltiplas "vozes" que nele ecoam, apreender no fragmento descontinuo a ressonância de outros contextos. A lexia é, pois, essa unidade que o leitor recorta ao sabor da leitura, e a partir da qual produz uma estrutura móbil das conotações que configuram o caráter plural do texto.

6 O termo internet corresponde à rede mundial de comunicação por meio de computadores. 
de um documento eletrônico, como uma palavra, uma frase ou um gráfico, que contém o endereço de outro documento eletrônico. A conexão destes fragmentos com outros pode estabelecer uma base de sentidos possíveis. O "link eletrônico" possibilita uma leitura multilinear ou multi-seqüencial, cuja seqüência dos conteúdos na hipermidia é definida pelo usuário.

A união de uma informação dada com a subseqüente é uma preocupação encontrada nos trabalhos de Lev Manovich, que excursiona pela história do cinema para estabelecer relações deste com o que ele define por novas mídias. Abordando também a questão da hipermídia, o teórico discorre sobre a possibilidade de ambientes informatizados permitirem que os usuários selecionem elementos multimidiáticos que se ligam a outros através dos hyperlinks, num esquema labiríntico, em que uma estrutura independente pode se conectar à outra, resultando em uma versão particular de um documento. No cinema, um filme também pode apresentar algum elemento visual ou sonoro que se liga a outros pertencentes ao mesmo filme, de uma maneira coerente ou não, bem como elementos que se conectam a outros referenciais fora do contexto do filme. Um enunciado filmico pode conter informações que estabelecem uma relação intertextual em que um segmento expressivo do filme reporte a um link relativo a um outro contexto. Um dos filmes que ilustra a teoria de Manovich é Man with a Movie Camera (1929), de Dziga Vertov. $\mathrm{O}$ teórico analisa o filme como um meio de expressão que contém diversos apontamentos relacionados com as novas mídias, como a justaposição de imagens e a questão da intertextualidade possibilitada por determinados enunciados. O próprio enquadramento é comparado a um écran em abismo, em que a partir de um plano ou de sua ligação com o anterior ou o subseqüente, os significados enunciados da representação visual ou sonora podem remeter à enunciação filmica, como, por exemplo, quando um filme articula planos sem uma ligação temporal e espacial lógica ou utiliza planos que mostram a formação de múltiplas perspectivas, permitindo que o espectador atualize e amplie os significados dados.

O cinema, mesmo apresentando uma estrutura narrativa que fornece diversos pontos de vista sobre um mesmo fato, é um veículo 
que não permite um leque de combinações ilimitadas ao espectador. Isto ocorre devido à estabilidade de um conjunto de diversas línguas ${ }^{7}$ presente no enunciado. Por outro lado, utilizando as idéias de Bakhtin, juntamente com as de Barthes $^{8}$, fica dificil descartar a existência de uma instabilidade da língua em uso, representada por um enunciado que se formaliza a partir de enunciações denunciadas pela circularidade cultural e pela multiplicidade de visões de mundo. Tanto os trabalhos de Bakhtin como os de Barthes são de extrema importância para discutir certas particularidades relacionadas à questão da multilinearidade das narrativas, principalmente com o advento das novas tecnologias que permitem a intersecção de ambientes multimidiáticos, o que abre um novo campo de pesquisa sobre o desdobramento de narrativas ficcionais.

O teórico do hipertexto, George Landow, relata que, na tentativa de imaginar a experiência de escrita e de leitura com (ou sem) esta nova forma de texto, não se pode deixar de enfocar o que Bakhtin discorreu sobre o dialogismo e a polifonia nos romances, em que afirma que "são construídos levando em conta não apenas uma única consciência que absorve outras, mas como uma totalidade formada pela interação de várias consciências, das quais nenhuma se torna por completo objeto da outra" (Landow, 1995, p. 23). Bakhtin iluminou a discussão sobre o hipertexto com relação a um importante questionamento desenvolvido nas suas teorias sobre o romance: nem o romance, nem uma estrutura multimidiática permitem uma única e tirana voz, pois o momento focalizado sempre permite que experiências outras se combinem. No romance de Dostoievski, como na ficção hipertextual, vozes individuais tomam a forma de lexias que vão continuamente formando narrativas ao longo do caminho da leitura. Landow também coloca que a concepção de textualidade bakhthiniana antecipou o hipertexto: o texto como um todo não é uma identidade

7 O cinema é um sistema formado por um conjunto de línguas diferentes que ocorrem simultaneamente no suporte película, que podem ou não ter ligações. Por exemplo, um sistema (imagem) pode se referir a um tempo relacionado a outro sistema (música), como é o caso da voz acusmática, uma fonte sonora na qual insinua, mas não relata de forma clara sua origem.

8 Bakhtin e Barthes são os dois principais autores que fornecem subsídios teóricos para a atual discussão sobre as novas mídias. 
acabada, mas sempre uma relação. Portanto, o todo nunca pode ser finalizado, pois quando se pensa que este se realizou, percebe-se que ele continua aberto a novas mudanças (Landow, 1995, p. 81).

Os trabalhos de Barthes também assumem uma extrema importância para esses estudos atuais, principalmente pelas suas discussões que circundam o conceito de escrita, que são de extrema importância no contexto das novas mídias digitais. Landow (Landow, 1995 , p. 15 ) discute a questão do "texto ideal" desenvolvido por Barthes no livro $S / Z$, como um conceito primordial para a compreensão deste novo meio:

...neste texto ideal, emanam as redes que se interagem entre si, sem que nenhuma possa impor-se às demais: este texto é uma galáxia de significantes e não uma estrutura de significados. Não tem principio, mas diversas vias de acesso, sem que nenhuma delas possa qualificar-se de principal. Os códigos que mobiliza estendemse até aonde alcança a vista, são intermináveis. Os sistemas de significados só podem surgir deste texto absolutamente plural e ilimitado, já que está baseado na infinitude da linguagem. (Barthes, 1992, p. 39)

A noção barthesiana de escrita identifica como lexia a ligação de um bloco de texto com outros, o que parece combinar perfeitamente com o que é chamado de hipermídia - textos compostos de blocos de palavras (ou imagens, sons, etc) unidos eletronicamente através de links, reportando a múltiplos caminhos possíveis.

Um dos apontamentos do presente estudo é estabelecer que as lexias presentes em uma obra hipermidiática não são características específicas das novas mídias digitais. No cinema existem filmes que apresentam lexias "linkadas" a outras lexias presentes dentro ou fora do seu enunciado. Na maioria das vezes, este processo de relação requer uma atualização de significados e depende da interação do espectador com o filme para se constituir. Na hipermídia é possível acontecer o mesmo que no cinema. Porém, os links podem ser identificados com maior facilidade pelos sinais gráficos ou sonoros, 
mostrando de maneira mais explícita a indicação de um link que conecta a outro contexto. Segundo Gosciola, os links podem ser identificados na hipermidia da seguinte maneira (Gosciola, 2003, p. 161):

- realce ou inversão de um ícone ou palavra;

- negrito ou sublinhado;

- moldura em volta da palavra como link;

- mudança de cor;

- lista de palavras com links, como índices, glossários, etc;

- tela reduzida de um trecho ou frame de vídeo que, ao ser clicada, inicia a exibição, ou o download, ou o streaming;

- icones ou botões para clicar;

- anotações marginais ou títulos;

- um clique em um gráfico ou uma figura;

- um ruído sonoro diferenciado.

$\mathrm{Na}$ internet, os conteúdos são conectados de antemão. No cinema, as lexias aparecem de maneira mais sutil e dependem do desempenho e da curiosidade do espectador para serem ativadas ou não. É difícil fornecer uma lista que determine as características dos links no cinema. Tudo vai depender da estrutura do filme, se é ou não um filme que permite a abertura para outros conteúdos e como isto se processa. $O$ que pode ser colocado é a ênfase a alguns elementos de composição visual e sonora que, muitas vezes, parecem chamar a atenção para outros contextos e que são explorados também pelas novas mídias:

- o título do filme: tentativa de se estabelecer alguma relação do título do filme com a história contada e ampliar este contexto para algo que está aquém ou além do próprio filme;

- os movimentos de câmera: a câmera pode assumir pontos de vista que são completamente impossíveis de ser remetidos a um olhar de uma pessoa, como angulações inusitadas relacionadas às câmeras baixas, quando a câmera filma de baixo para cima, ou às câmeras altas, quando filma de cima para baixo, ou mesmo de uma perspectiva aérea. Este posicionamento da câmera pode provocar uma estranheza no espectador, que fica intrigado em saber da onde vem aquele olhar diferenciado, chamando a atenção para conteúdos que podem estar fora do universo ficcional; 
- o plano-seqüência: a evolução tecnológica dos movimentos de câmera, como, por exemplo, os realizados pelo steady-cam ${ }^{9}$, permite que a câmera acompanhe uma situação dramática de diversos pontos de vista em plano-seqüência, isto é, a continuidade espacial estabelecida pela utilização de um único plano gaṛante a coincidência da temporalidade representada com a (supostamente) real. O plano-seqüência tem uma profunda relação com os videogames e os ambientes em VRLM (realidade virtual), pois a maneira como o usuário imerge no universo do jogo é quase sempre constituída de um longo plano-sequência que o absorve durante a sua jornada. É interessante notar que no início do cine$\mathrm{ma}$, antes dos realizadores descobrirem o potencial do cinema através da decupagem dos planos, os filmes também eram realizados em uma única tomada. Vale a pena lembrar que Hitchcock foi um dos primeiros idealizadores de um longa-metragem realizado em plano-seqüência, o filme Festim Diabólico (The Rope, 1948). Este filme retrata a tentativa de construir uma narrativa fílmica em um único plano-seqüência, um desafio para a época, pois produzir um filme de longa-metragem sem cortes era algo tecnologicamente inconcebível devido à limitação dó tamanho do rolo do filme (com duração de 20 minutos). Esta característica obrigou o diretor a utilizar certos recursos para mascarar o corte que era necessário para juntar os rolos, como finalizar um plano com uma imagem totalmente preta que possibilitava a união com o início, também em preto, de outro plano, fornecendo a impressão de não haver cortes. Atualmente, o espectador está mais familiarizado com histórias narradas a partir de um conjunto de planos que são concebidos e montádoś com a finálidadé de construir uma relação artificial entre o tempo da representação e tempo representado, propiciando um efeito de continuidade temporal. Assim, um filme pode utilizar um único plano èm determinada cena para causar um impacto com relação às outras cenas compostas pela articulação de vários planos, o que pode ser visto como um link para outros contextos fora do filme;

9 Equipamento que é preso ao corpo do operador e realiza longos movimentos de cầmara sem trepidação. 
- sobreposição de imagens e sons: é uma técnica encontrada em diversos filmes e é interessante de ser explorada como um link que questiona o poder ilusório do cinema. Pode ocorrer de diferentes maneiras:

a) sobreposição de ações: quando cenas diferentes são sobrepostas em um mesmo plano, pela utilização de fusão ou mesmo de trucagem. No início do século XX, o realizador francês Georges Méliès foi um dos criadores desta técnica, mas não se pode deixar de citar mais uma vez ofilme Um Homem com uma Câmera, de Vertov, como um importante explorador da linguagem cinematografica.

Este fotograma (fig. 1) faz parte do filme de Vertov e de-

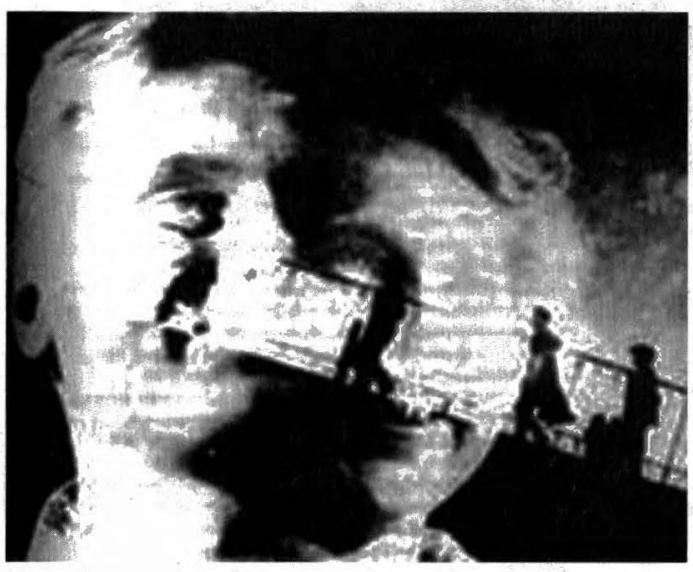

Figura 1

monstra como o recurso da sobreposição de ações causa uma inquietação, tanto do olhar como da cognição do espectador em estabelecer ligações entre as diversas imagens que são articuladas simultaneamente no mesmo plano. Estes recursos são freqüentemente encontrados na com-

posição da linguagem das novas mídias.

A sobreposição de ações também pode ser realizada pela exploração do uso da profundidade de campo, em que duas ou mais cenas simultâneas são encenadas em diferentes espaços dentro de um mesmo plano, como, por exemplo, uma cena que ocorre mais à frente do plano e outra mais ao fundo. O filme Cidadão Kane (1941), de Orson Welles, é um dos mais citados como precursor desta técnica.

No fotograma do filme de Welles (fig. 2), várias ações ocorrem em diferentes espaços do quadro. Em primeiro plano, a mãe de Kane, à direita do quadro, assina os papéis referentes à transferência 
da guarda do filho. O pai está posicionado à esquerda da mãe, mais ao fundo do quadro, e observa a ação da mulher. Mais centralizado e

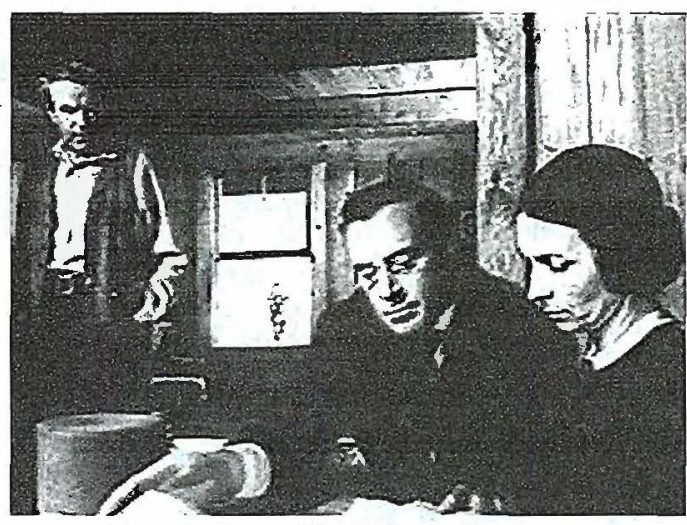

Figura 2 ao fundo do quadro, pela moldura de uma janela, está o menino Kane, que brinca com o seu trenó na neve. Aqui, três ações ocorrem simultaneamente no mesmo quadro, o que obriga o espectador a percorrer com os olhos os vários contextos, além de permitir possíveis conexões com outros conteúdos, dentro e fora do universo ficcional.

Outrŏ filme que também teve uma importante repercussão, tanto pelo uso de ações simultâneas nos espaços em profundidade quanto pela implicação de espaços fora do quadro, é $A$ Regra do Jogo (1939), de Jean Renoir. Estas técnicas, além de permitirem mais ambigüidade porque a atenção do espectador passa a ter várias direções, apontam para conteúdos que vão além dos representados na tela retangular do cinema.

b) Sobreposições de planos: este recurso implica na sobreposição não apenas de cenas filmadas, mas de outros elementos como textos e grafismos em movimento. Este tipo de disposição.é muito comum em

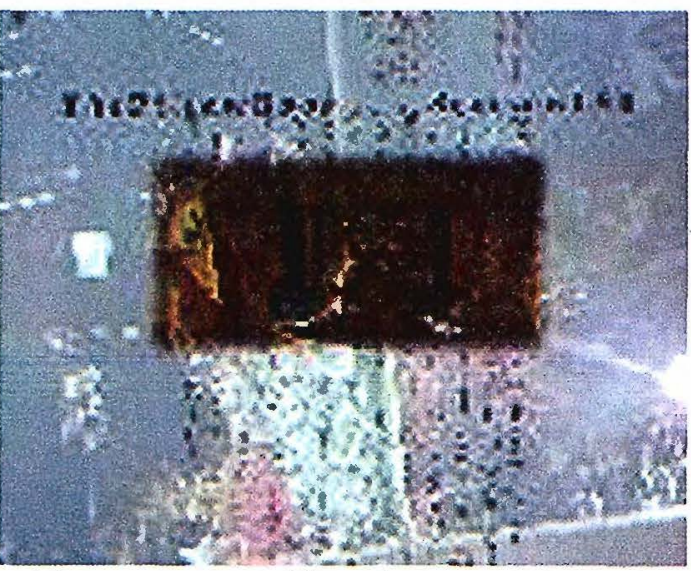

Figura 3 
ambientes hipermidiáticos, como os sites da Web, por exemplo. No cinema, filmes como A Última Tempestade (1991), de Peter Greenaway, utilizam a sobreposição de textos ou de planos dentro de outro plano (fig. 3), o que faz com que o espectador participe de uma maneira mais ativa e correlacione as informações dadas.

c) Encadeamento simultâneo de planos: dois ou mais planos são inseridos num mesmo plano e mostram ações que ocorrem de maneira simultânea. O filme Napoleão (1927), de Abel Gance, foi um dos pioneiros na utilização deste recurso, colocando três ações simultâneas lado a lado em um mesmo plano, denominado de tela tríplice (fig.4).
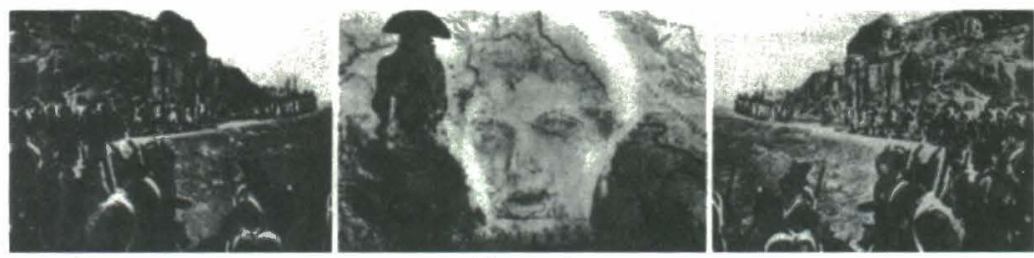

Figura 4

Outro filme mais recente que também utiliza esta técnica, mas ao invés de dividir a tela em três, a divide em quatro, é Time Code (2000), de Mike Figgis. Neste filme, as histórias paralelas ocorrem simultaneamente em telas contíguas (plano-sequiência) e o espectador pode selecionar o que quer ver, de acordo com o seu interesse ou à medida que o som de uma das partes se faz mais audível (fig. 5).

- close-ups ou planos de detalhes: os planos muito fechados ou planos de detalhe de algum elemento em cena, caso não sejam conectados com o seu contexto por meio de um plano mais aberto, podem exigir um esforço do espectador em relacionar o

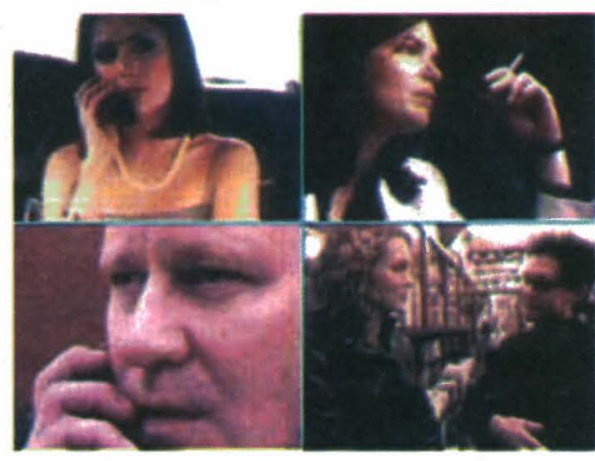

Figura 5 
que vê com algo que está fora da tela, implicando em uma ligação para além do conteúdo inicial;

- iluminação: elemento que contribui com a representação da profundidade de campo e com a dramaticidade da cena. Um recurso de composição que possibilita a criação de planos e profundidades, além de modelar o relevo das figuras presentes no quadro, permitindo uma percepção mais evidente dos espaços existentes entre os elementos. No cinema, a iluminação, mais do que um recurso que permite que as ações sejam vistas, é usada para moldar ou dar formas tridimensionais aos objetos. Áreas claras e escuras ajudam a criar composições dentro do quadro e a conduzir nossos olhos para certos elementos e ações. A fotografia fílmica trabalha com várias fontes de luz para criar ambientes iluminados próximos à percepção da realidade e sugerir o volume dos corpos, a característica espacial do cenário, a presença ou a ausência de algum elemento do plano.

Os filmes expressionistas, por exemplo, utilizam um contraste agressivo entre o claro e escuro, como o isolamento de algum elemento do quadro pela incidência de uma ofuscante brancura em contraposição à outra parte negra e sombria, para aumentar o impacto dramático no que diz respeito à representação das próprias contradições inerentes ao comportamento de determinados personagens. No filme expressionista $O$ Gabinete do Dr. Caligari (1920), de Robert Wiene, o contraste entre claro e escuro produz

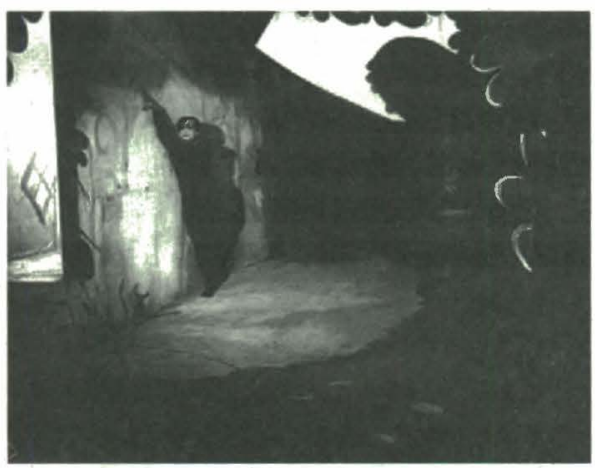

Figura 6 um efeito que demonstra uma perturbação relativa às próprias características internas e específicas do personagem que está na zona iluminada, gerando nitidamente a impressão de um processo de embate entre o mundo interior e exterior, entre fantasia e realidade, entre vida e morte (fig 6). 
Tanto no cinema quanto nas novas mídias digitais encontram-se obras que têm a intenção de instituir uma lógica que permite a reconstrução, o estabelecimento de relações significativas entre as diferentes lexias e suas potencialidades em constituir ou antecipar experiências novas. Atualmente, a busca de conexões entre diferentes contextos tornou-se um procedimento comum, principalmente com a evolução inicial das novas mídias. Tentar ampliar a investigação de algum assunto específico tornou-se muito fácil a partir da sua exploração em ambientes multimídias (cd-rom) ou na própria internet. Por exemplo, uma palavra pode aparecer como uma lexia, que sendo "clicada" pelo mouse remete a outras informações sobre um contexto em comum. Ao se buscarem referências sobre esta forma de comunicação labiríntica, da qual, de uma proposta inicial pode-se saltar de várias maneiras e chegar a conclusões distintas, percebe-se que isto não é uma inovação surgida com o advento das novas tecnologias.

Os videogames são exemplos de novas mídias que incorporam a linguagem do cinema. É muito comum encontrar a utilização de técnicas tradicionais do cinema nos videogames, como o uso expressivo das angulações de câmera, da profundidade de campo e da utilização da luz como elemento dramático. $O$ computador permite a mobilidade do enquadramento, uma invenção do cinema, mas mais do que um ponto de vista pré-determinado, são dadas ferramentas que permitem ao usuário mover-se pelo espaço, adentrar por diferentes regiões e visualizar diferentes conteúdos na tela. $\mathrm{O}$ usuário tem a sensação de fazer parte daquele espaço diegético, em que pode escolher livremente trajetórias e pontos de vista. $\mathrm{Na}$ realidade, como no cinema, esta livre escolha ainda é restrita. Existem caminhos aos quais o usuário não tem acesso, porém existe uma espécie de autonomia maior do que no cinema, em que a obra já está acabada.

Muitos são os recursos da linguagem cinematográfica utilizados para constituir as mídias digitais. Porém, ainda existe uma enorme dificuldade em se determinar uma linguagem estável para este novo meio, principalmente pela sua constante evolução e a incessante introdução de novas técnicas. É possível afirmar-se que, diferentemente do cinema, a pessoa que opta em navegar por um ambiente hipermidiático sabe que está excursionando por um universo labiríntico 
e está consciente da impossibilidade da existência de uma única história. Em contato com narrativas interativas digitais, a atitude passiva de um espectador que apenas imerge em um mundo ficcional e se deixa levar por ele, um processo inerente à estrutura do cinema clássico, é transformada como se estivesse em contato com filmes que o incitam a refletir e a dialogar com o seu conteúdo. As novas mídias utilizam recursos narrativos e estéticos existentes em diversos filmes que apresentam a proposta de não fechar um sentido em si mesmo, fornecendo diferentes pontos de vista de uma mesma situação dramática. Na obra hipermidiática, e também em muitos filmes, ao usuário não basta apenas imergir na diegese, e sim participar ativamente de um universo que, mesmo delimitado, necessita de suas escolhas para se constituir.

\section{Bibliografia}

BAIRON, S.; PETRY, L. C. 2000. Hipermídia: psicanálise e história da cultura. São Paulo: Editora Mackenzie.

BAKHTIN, M. M. 1981. Problemas da poética de Dostoiévski. Rio de Janeiro: Forense-Universitária.

BARTHES, R. 1979. O sistema da moda. São Paulo: Ed. Nacional/ USP

1992. S/Z. Rio de Janeiro: Nova Fronteira.

BILBAO, J. I. L. 2000. "Narrativa no-lineal e interacción textual." Trípodos: llenguatge, pensamente, comunicació, Barcelona: Facultat de Ciêncies de la Comunicació/Universitat Ramon Líull, extra, p. 431-441.

CAÑIZAL, E. P. 1998. "La voix dans le mirroir: le dialogisme métaphorique." Recherches Sémiotique - Semiotic Inquiry, v. 18 , números $1-2$.

FELIPE, F. 2000."A las puertas del cine interactivo: video juegos y narrativa potencial." Trípodos: llenguatge, pensamente, comunicàcióo. Barcelona: Facultat de Ciêncies de la Comunicació/ Universitat Ramon Llull, extra, p. 497-508. 
GOSCIOLA, V. 2003. Roteiro para as novas midias: do game à TV interativa. São Paulo: Senac.

LANDOW, G. 1995. Hipertexto: la convergencia de la teoría critica contemporánea y la tecnología. Barcelona: Ediciones Paidós.

MANOVICH, L. 2001. The Language of new media. Massachusetts: MIT Press.

MURRAY, J. H. 1997. Hamlet on the holodeck: the future of narrative in cyberspace. New York: Free Press.

STAM, R.; BURGOYNE, R.; FLITTERMAN-LEWIS, S. 1999. Nuevos conceptos de la teoría del cine. Barcelona: Paidós.

\section{Filmografia}

Amores possiveis. 2001. Sandra Werneck.

A regra do jogo. 1939. Jean Renoir.

A última tempestade. 1991. Peter Greenaway.

Boca de ouro. 1968. Nelson Pereira dos Santos.

Cidadão Kane. 1941. Orson Welles.

Corra Lola, corra. 1998. Tom Tykwer.

Efeito borboleta. 2004. Eric Bress e J. Mackye Gruber.

Festim diabólico. 1948. Alfred Hitchcock.

O gabinete do Dr. Caligari.1920. Robert Wiene.

Rashmon. 1950. Akira Kurosawa.

Time code. 2000. Mike Figgis.

Um homem com uma câmera.1929. Dziga Vertov 